\title{
Pulmonary Outcomes in Survivors of Childhood Cancer
}

\author{
A Systematic Review
}

\author{
Tseng-Tien Huang, PhD; Melissa M. Hudson, MD; Dennis C. Stokes, MD; \\ Matthew J. Krasin, MD; Sheri L. Spunt, MD; and Kirsten K. Ness, PhD
}

\begin{abstract}
Background: The purpose of this article is to summarize the literature that documents the longterm impact of cancer treatment modalities on pulmonary function among survivors of cancer and to identify potential areas for further research.

Methods: Systematic reviews of clinical trials, observational studies, case series, and review articles were conducted. Articles were limited to the studies that discussed pulmonary toxicity or late effects among pediatric cancer survivors and to follow-up investigations that were conducted a minimum of 2 years after completion of cancer-related treatment or 1 year after hematopoietic stem cell transplant.

Results: Sixty publications (51 clinical studies/reports and nine reviews) published from January 1970 to June 2010 in PubMed met the inclusion criteria. Data showed an association between radiotherapy, alkylating agents, bleomycin, hematopoietic stem cell transplant, and thoracic surgery and pulmonary toxicity, as well as possible interactions among these modalities.

Conclusions: Pulmonary toxicity is a common long-term complication of exposure to certain anticancer therapies in childhood and can vary from subclinical to life threatening. Pulmonary function and associated loss of optimal exercise capacity may have adverse effects on long-term quality of life in survivors. Lung function diminishes as a function of normal aging, and the effects of early lung injury from cancer therapy may compound these changes. The information presented in this review is designed to provide a stimulus to promote both observational and interventional research that expands our knowledge and aids in the design of interventions to prevent or ameliorate pulmonary late effects among survivors of childhood cancer. CHEST 2011; 140(4):881-901

Abbreviations: $\mathrm{ALL}=$ acute lymphoblastic leukemia; $\mathrm{BCNU}=$ carmustine; $\mathrm{CCNU}=$ lomustine; DLCO = diffusing capacity of the lung for carbon monoxide; GVHD = graft-vs-host disease; gy = gray; HL = Hodgkin's lymphoma; HSCT $=$ hematopoietic stem cell transplant; NHL = non-Hodgkin's lymphoma; PFT = pulmonary function testing; TLC = total lung capacity
\end{abstract}

O ver the last 3 decades, therapeutic progress has resulted in a growing population of survivors of childhood cancer. In 2006, there were $>11$ million cancer survivors in the United States, three times the number of survivors in $1971 .{ }^{1}$ The 5 -year survival

Manuscript received August 17, 2010; revision accepted March 1, 2011.

Affiliations: From the Department of Epidemiology and Cancer Control (Drs Huang and Ness), the Department of Oncology (Drs Hudson and Spunt), the Department of Pediatric Pulmonary Medicine (Dr Stokes), and the Department of Radiological Sciences (Dr Krasin), St. Jude Children’s Research Hospital, Memphis, TN.

Funding/Support: The authors have reported to CHEST that no funding was received for this study.

rate for children diagnosed with cancer is approaching $85 \%,{ }^{2}$ and an estimated one in 570 individuals in the United States between the ages of 20 and 34 is a survivor of childhood cancer. ${ }^{3}$

Unfortunately, increased survival rates are not without consequences. There is substantial evidence

Correspondence to: Tseng-Tien Huang, PhD, Department of Epidemiology and Cancer Control, St. Jude Children's Research Hospital, Mail Stop 735, 262 Danny Thomas Place, Memphis, TN 38105; e-mail: tseng.huang@stjude.org

(C) 2011 American College of Chest Physicians. Reproduction of this article is prohibited without written permission from the American College of Chest Physicians (http://www.chestpubs.org/ site/misc/reprints.xhtml).

DOI: $10.1378 /$ chest.10-2133 
that survivors of childhood cancer are at risk of developing various severe, disabling, or life-threatening conditions later in life. ${ }^{4-6}$ Cancer treatment-related complications represent a major cause of morbidity that can have a profound effect on quality of life and can predispose to early mortality during adulthood. In a large-scale retrospective study of 5-year cancer survivors $(N=20,483)$, Armstrong et al ${ }^{4}$ reported significant excess rates of death largely due to treatmentrelated causes rather than recurrence or progression of primary disease. Of note, pulmonary causes accounted for excess mortality risk (standard mortality ratio, 8.8), second only to deaths from subsequent cancers (standard mortality ratio, 15.2). ${ }^{4}$ Chemotherapy and radiotherapy used to treat children with cancer can cause permanent lung damage. ${ }^{7-9}$ The cumulative incidence of pulmonary complications increases with increasing time since diagnosis, suggesting that survivors of childhood cancer continue to face new-onset pulmonary morbidity as they age. ${ }^{10}$

This review provides a synopsis of current knowledge on the adverse effects on the lung of childhood cancer and its treatment. We summarize treatment modalities associated with pulmonary toxicity and review how these agents may interact and contribute to permanent lung dysfunction in adult survivors of childhood cancer. We also discuss other risk factors for pulmonary morbidity and mortality in this population, and identify knowledge deficits that should be addressed in future research to benefit the childhood cancer survivor population at risk of pulmonary late effects.

\section{Materials AND Methods}

\section{Criteria for Inclusion}

We considered only the studies that discussed pulmonary toxicity or late effects among individuals with childhood-onset cancer and limited those to follow-up investigations that were conducted a minimum of 2 years after completion of cancer-related treatment or 1 year after hematopoietic stem cell transplant (HSCT). The primary outcome was defined as the occurrence of the pulmonary complications and a change in pulmonary function testing (PFT) results from serial evaluations.

\section{Search Strategies}

We searched the PubMed database (January 1970 to June 2010) for clinical trials, observational studies, case series, and reviews to include in our review. The key words "late effects" or "late sequelae" or "complications" AND "child" or "childhood" AND "cancer survivor" AND "lung" or "thorax" or "pulmonary" were combined with keywords for each therapeutic exposure. Accordingly, the keywords "radiation," "radiotherapy," or "ionizing radiation" were selected for radiation exposure; "chemotherapy" or "combined chemotherapy" for chemotherapy exposure; "stem cell transplant," "bone marrow transplant," "allogeneic" and/or "autologous bone marrow transplant" for HSCT; and "surgery," "resection," and/or "lobectomy" for surgery exposure. Reference lists of review articles and retrieved studies were also assessed for relevant titles.

\section{Validity Assessment and Data Extraction}

One author (T. H.) screened all retrieved reports and selected those that were potentially valid. To ascertain the validity of included studies, two authors independently assessed the selected studies for methologic quality. ${ }^{11}$ Information was sought for the following four criteria: comparability of subject, clear definition of exposure or intervention, standard outcome measurement, and appropriate statistical analysis. The discrepancies of validity assessment were resolved by discussion. Of note, we were unable to use one of the Preferred Reporting Items for Systematic Review and MetaAnalysis commanded approaches, such as the Cochrane method for the assessment of risk of bias, because literature in this area includes many observational and few randomized studies. For each included study, patient characters, antitreatment exposure, follow-up period, sample size, and main study results were extracted.

\section{RESULTS}

\section{Search Results}

The search of the PubMed database initially resulted in a total of 132 citations. After adjusting for duplicates, 130 remained. Of these, 76 studies were discarded because they did not meet the inclusion criteria (65 studies did not discuss pulmonary toxicity among childhood-onset cancer; eight studies investigated follow-up late effects no more than 2 years after completion; three studies investigated late effects among childhood cancer survivors within 1 year after HSCT). Another three papers were discarded because their full texts were not available. The reference lists of the remaining 51 studies were examined, and nine additional studies were identified that met the inclusion criteria. Thus, 60 publications ( 51 clinical studies/reports and nine reviews) from January 1970 to June 2010 were included in this review.

\section{Description of Studies}

Of 51 clinical studies, nine were prospective studies; the others were observational studies, except for one self-report study. No prior systematic review or meta-analysis on the adverse effects of childhood cancer and its treatment on the lung was identified. The treatment protocols varied by institution, classification, and timing of the primary diagnosis. The adverse effects of anticancer therapy on the lungs ranged from subclinical abnormalities on PFT to disabling and life-threatening pulmonary syndrome. The research demonstrated an association between radiotherapy, alkylating agents, bleomycin, HSCT, and thoracic surgery and pulmonary late effects among survivors of childhood cancer. 


\section{Study Quality and Risk of Bias}

Table 1 provides an overview of study quality in the included publications. Overall, the included studies demonstrated a clear definition of exposure, valid outcome measure, and appropriate statistical analysis. Unfortunately, our ability to compare study populations was limited because many of the articles we located included single- or limited multi-institutional data derived from retrospective or cross-sectional investigations with samples of convenience. Additionally, the data presented from the earlier studies may not be relevant to current practice, because treatment of childhood cancer has changed substantially over time. Furthermore, because many studies were cross-sectional in nature, survivor bias may have excluded patients with more severe complications from PFT measurements at later time points. Nevertheless, this literature has value because the information helps define the extent and patterns of pulmonary dysfunction observed in adult survivors of childhood cancer, and offers clues about possible risk factors for long-term lung complications in this cohort.

\section{DISCUSSION}

\section{Summary of Evidence}

Table 2 provides the summary of this systematic review. The results shows that certain therapeutic exposures, such as radiotherapy, specific alkylating agents, bleomycin, HSCT, and thoracic surgery, are linked to late pulmonary sequelae.

\section{Disease- and Treatment-Induced Pulmonary Toxicity in Survivors of Childhood Cancer}

Pulmonary dysfunction in survivors of childhood cancer results from primary or metastatic disease, antineoplastic therapy, and superimposed infections. Primary lung tumors are exceptionally rare in children. ${ }^{63}$ However, the lung is a common site for metastases, even years following treatment. ${ }^{64}$ Pulmonary toxicity as a result of anticancer therapy may range in severity from subclinical abnormalities on PFT to disabling and life-threatening pulmonary syndromes. Although pulmonary complications are essentially preventable by limiting the administration of offending drugs and irradiation, toxicity may be unavoidable if the toxic modalities are required to optimize tumor control.

Late Effects of Radiation in Survivors of Childhood Cancer: The late effects of radiation exposure are particularly important in children because both impaired organ development and skeletal growth defects may occur and magnify the problems related to lung injury. Self-reported data from 12,000 survivors in the Childhood Cancer Survivor Study showed that, compared with siblings, survivors treated with chest radiation had a fivefold increased risk of abnormal chest wall development ( $\mathrm{RR}=5$; 95\% CI, 2.7-9.4), a fourfold excess risk of developing lung fibrosis $(\mathrm{RR}=4.3$; 95\% CI, 2.9-6.6), and a twofold excess risk of chronic pneumonia ( $\mathrm{RR}=2.2 ; 95 \% \mathrm{CI}, 1.5-7.0) .39$ In this cohort, the cumulative incidence of lung fibrosis was $3.5 \%$ within 20 years of diagnosis.

Table 3 lists the 22 reports published from January 1970 to June 2010 on radiation-induced pulmonary late effects among survivors of childhood cancer. Data from early studies on children treated for metastatic Wilms tumor demonstrate that irradiation of the thorax primarily affects the lung parenchyma and results in reduced lung volume, ${ }^{13,14}$ impaired dynamic compliance, ${ }^{14}$ and deformity of both the lung and chest wall. ${ }^{12,14}$ The diffusing capacity of the lung for carbon monoxide (DLCO) may also be reduced. ${ }^{12}$ In 1992 , Attard-Montalto et $\mathrm{a}^{20}$ described lung function in eight survivors of Wilms tumor (follow-up, 14.8 years) who had received whole-lung irradiation at $15.3 \pm 1.8$ gray (Gy) in 10 to 14 daily fractions, and actinomycin, a radiomimetic chemotherapeutic agent. These children demonstrated small lung volumes but normal gas transfer per unit lung volume (lung diffusion capacity corrected for alveolar ventilation) when compared with predicted values for age and height. This suggests that although pulmonary irradiation in childhood leads to underdevelopment of the thorax, diffuse lung fibrosis is unlikely to be a significant feature at this dose level.

Patients receiving partial-lung irradiation are also at risk of developing radiation-induced pulmonary late effects. In a cross-sectional study of 47 survivors of childhood Wilms tumor, Shaw et al ${ }^{19}$ demonstrated that patients who had received partial-lung irradiation (20 Gy in 10 daily fractions) had significantly lower lung volumes than those who had received no irradiation. Lung diffusion capacity corrected for alveolar ventilation was significantly lower $(P<.05)$ in the whole-lung radiation group (12 Gy in eight daily fractions) than the partial-lung irradiation group, but other PFT parameters, such as $\mathrm{FEV}_{1}$, residual volume, and total lung capacity (TLC) were not significantly different between the two groups.

Although extensive data are available on lung function in adult survivors of Hodgkin's lymphoma (HL)/ non-Hodgkin's lymphoma (NHL), ${ }^{18,65-69}$ there are few studies on pulmonary function after childhood HL/NHL. Bossi et al ${ }^{26}$ reported that children with $\mathrm{HL}$ who received mediastinal irradiation of $>20 \mathrm{~Gy}$ and higher cumulative doses of chemotherapy had a high risk of developing lung function abnormalities. Nysom et $\mathrm{al}^{28}$ reported reduced TLC and DLCO in 


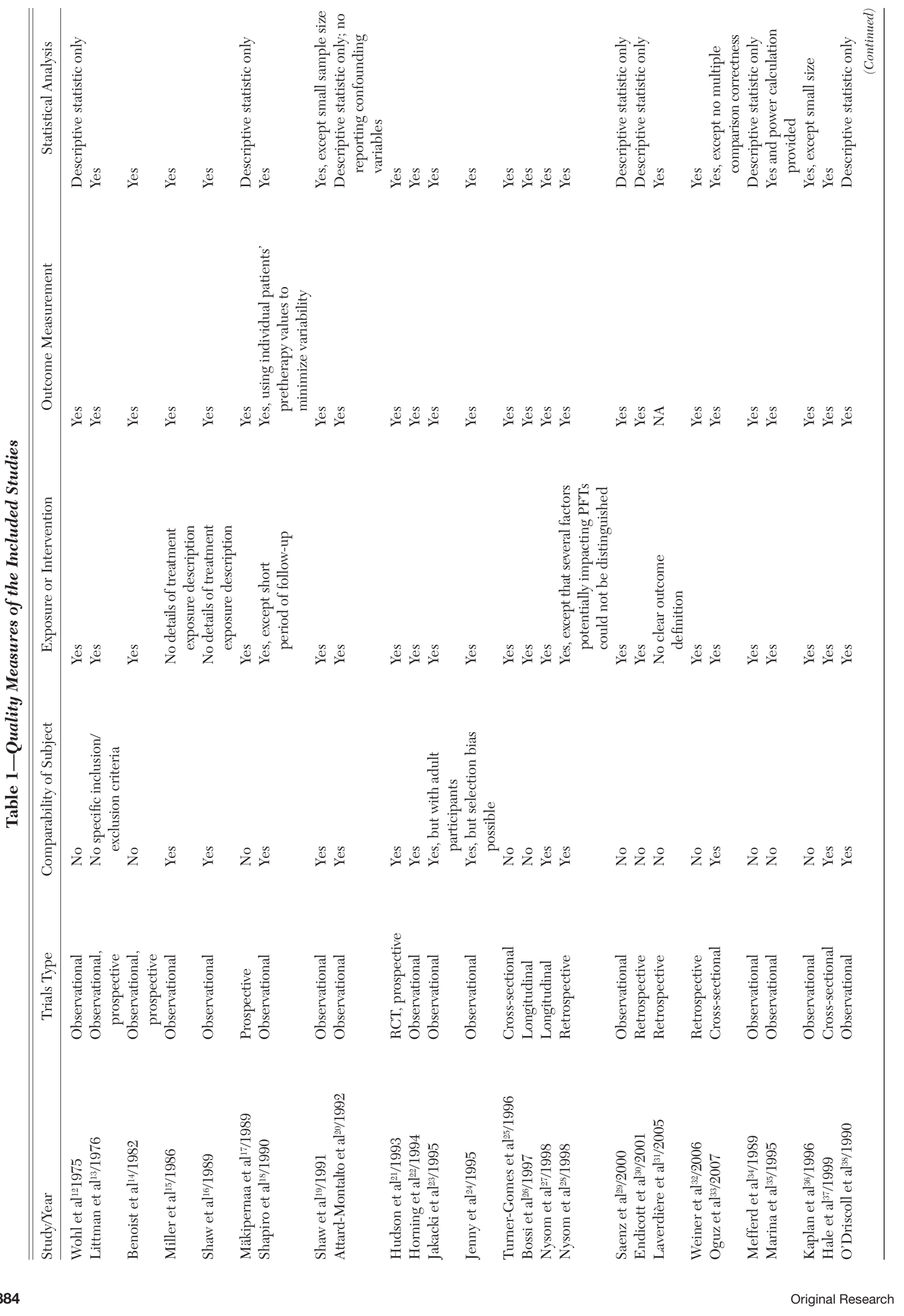




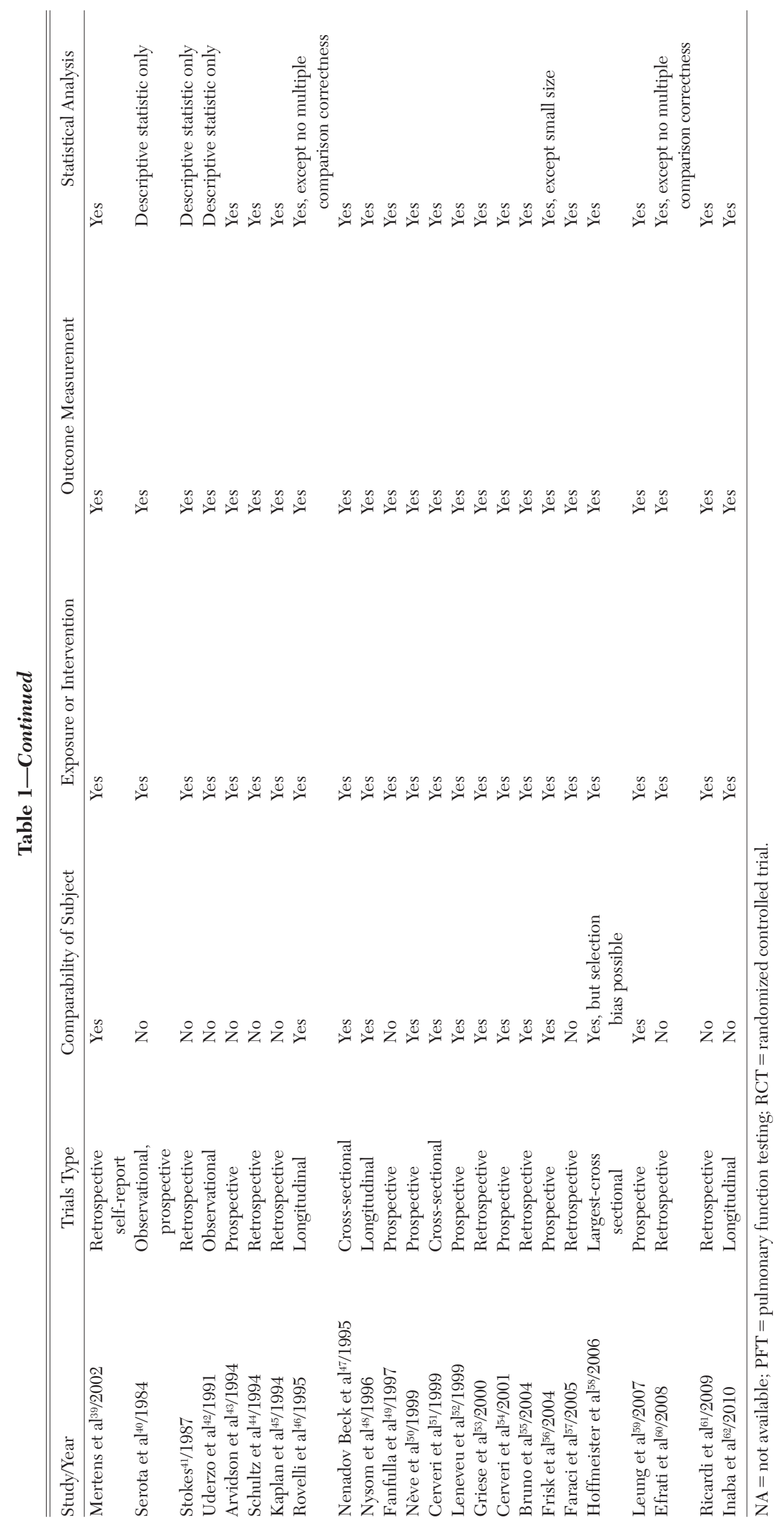


Table 2-Treatment Exposures-Based Risk Factors for Development of Late Effects in Survivors of Childhood Cancer

\begin{tabular}{|c|c|c|}
\hline Treatment Exposures & Potential Late Effects & Risk Factors \\
\hline Radiation & $\begin{array}{l}\text { Pulmonary toxicity } \\
\text { Pulmonary fibrosis } \\
\text { Interstitial pneumonitis } \\
\text { Restrictive lung disease } \\
\text { Obstructive lung disease }\end{array}$ & $\begin{array}{l}\text { Host factors } \\
\text { Younger age at irradiation } \\
\text { Treatment factors } \\
\text { Radiation dose } \geq 15 \text { Gy } \\
\text { Chest radiation combined with TBI } \\
\text { Radiation combined with } \\
\text { Bleomycin } \\
\text { BCNU } \\
\text { CCNU } \\
\text { Radiomimetic chemotherapy (eg, doxorubicin, dactinomycin) } \\
\text { Medical conditions } \\
\text { Atopic history } \\
\text { Health behaviors } \\
\text { Smoking }\end{array}$ \\
\hline $\begin{array}{l}\text { Alkylating agents: } \\
\text { Busulfan } \\
\text { BCNU }\end{array}$ & Pulmonary fibrosis & $\begin{array}{l}\text { Treatment factors } \\
\text { Higher cumulative doses }(>500 \mathrm{mg}) \text { combined with radiation } \\
\text { Medical conditions } \\
\text { Atopic history }\end{array}$ \\
\hline CCNU & & $\begin{array}{l}\text { Health behavior } \\
\text { Smoking }\end{array}$ \\
\hline Bleomycin & $\begin{array}{l}\text { Pulmonary toxicity } \\
\text { Interstitial pneumonitis } \\
\text { Pulmonary fibrosis } \\
\text { ARDS (very rare) }\end{array}$ & $\begin{array}{l}\text { Host factors } \\
\text { Younger age at treatment } \\
\text { Treatment factors } \\
\text { Higher cumulative doses }\left(\geq 400 \text { units } / \mathrm{m}^{2}\right) \text { combined with } \\
\text { Chest irradiation } \\
\text { Busulfan } \\
\text { BCNU } \\
\text { CCNU } \\
\text { Medical conditions } \\
\text { Renal dysfunction } \\
\text { High-dose oxygen support such as during general anesthesia } \\
\text { Health behavior } \\
\text { Smoking }\end{array}$ \\
\hline HSCT with any history of chronic GVHD & $\begin{array}{l}\text { Pulmonary toxicity } \\
\text { BO } \\
\text { BOOP } \\
\text { IPS } \\
\text { Restrictive lung disease } \\
\text { Obstructive lung disease }\end{array}$ & $\begin{array}{l}\text { Host factors } \\
\text { Younger age at HSCT } \\
\text { Treatment factors } \\
\text { Chest radiation } \\
\text { TBI } \\
\text { High-dose chemotherapy } \\
\text { Pulmonary toxic chemotherapy } \\
\text { Bleomycin } \\
\text { Busulfan } \\
\text { BCNU } \\
\text { CCNU }\end{array}$ \\
\hline $\begin{array}{l}\text { Surgery } \\
\text { Pulmonary lobectomy } \\
\text { Pulmonary metastasectomy } \\
\text { Pulmonary wedge resection }\end{array}$ & Pulmonary dysfunction & $\begin{array}{l}\text { Treatment factors } \\
\text { Combined with pulmonary toxicity therapy } \\
\text { Bleomycin } \\
\text { Busulfan } \\
\text { BCNU } \\
\text { CCNU } \\
\text { Medical conditions } \\
\text { Atopic history } \\
\text { Health behaviors } \\
\text { Smoking }\end{array}$ \\
\hline
\end{tabular}

$\overline{\mathrm{BCNU}}=$ carmustine; $\mathrm{BO}=$ bronchiolitis obliterans; $\mathrm{BOOP}=$ bronchiolitis obliterans organizing pneumonia; $\mathrm{CCNU}=$ lomustine; $\mathrm{GVHD}=$ graft-vs-host disease; Gy = gray; HSCT = hematopoietic stem cell transplant; IPS = idiopathic pneumonia syndrome; TBI = total body irradiation.

41 children treated for malignant lymphoma with chemotherapy with or without radiation. Oguz et al ${ }^{33}$ reported reduced lung volumes and DLCO among $13 \%$ (10 of 77 ) of survivors of childhood HL/NHL at a median 5 years post diagnosis.
Pulmonary Function and Loss of Optimal Exercise Capacity: Mild restrictive lung disease has also been reported as a potential outcome after treatment of childhood-onset acute lymphoblastic leukemia (ALL), and may eventually lead to reduced exercise capacity. 


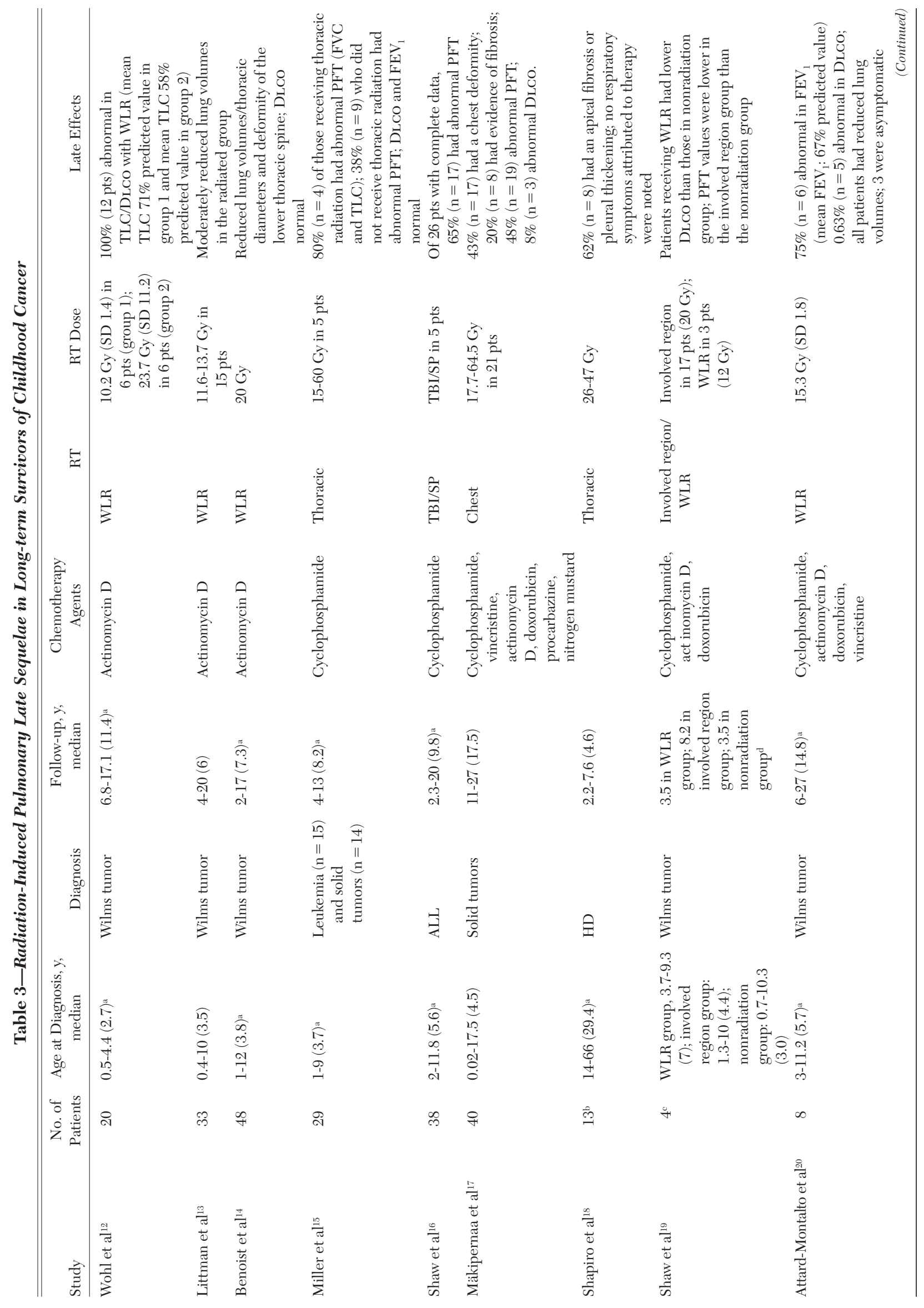




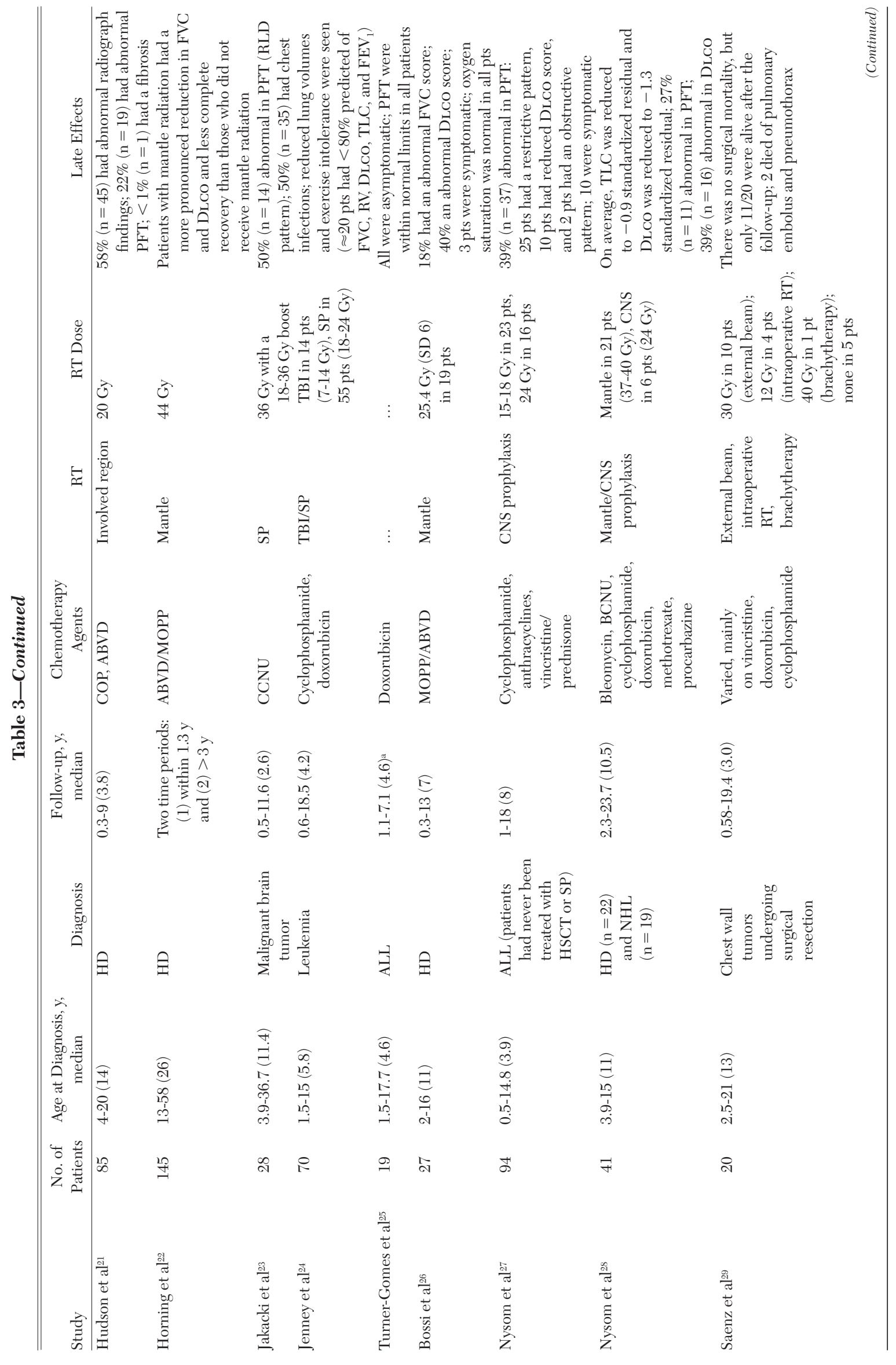




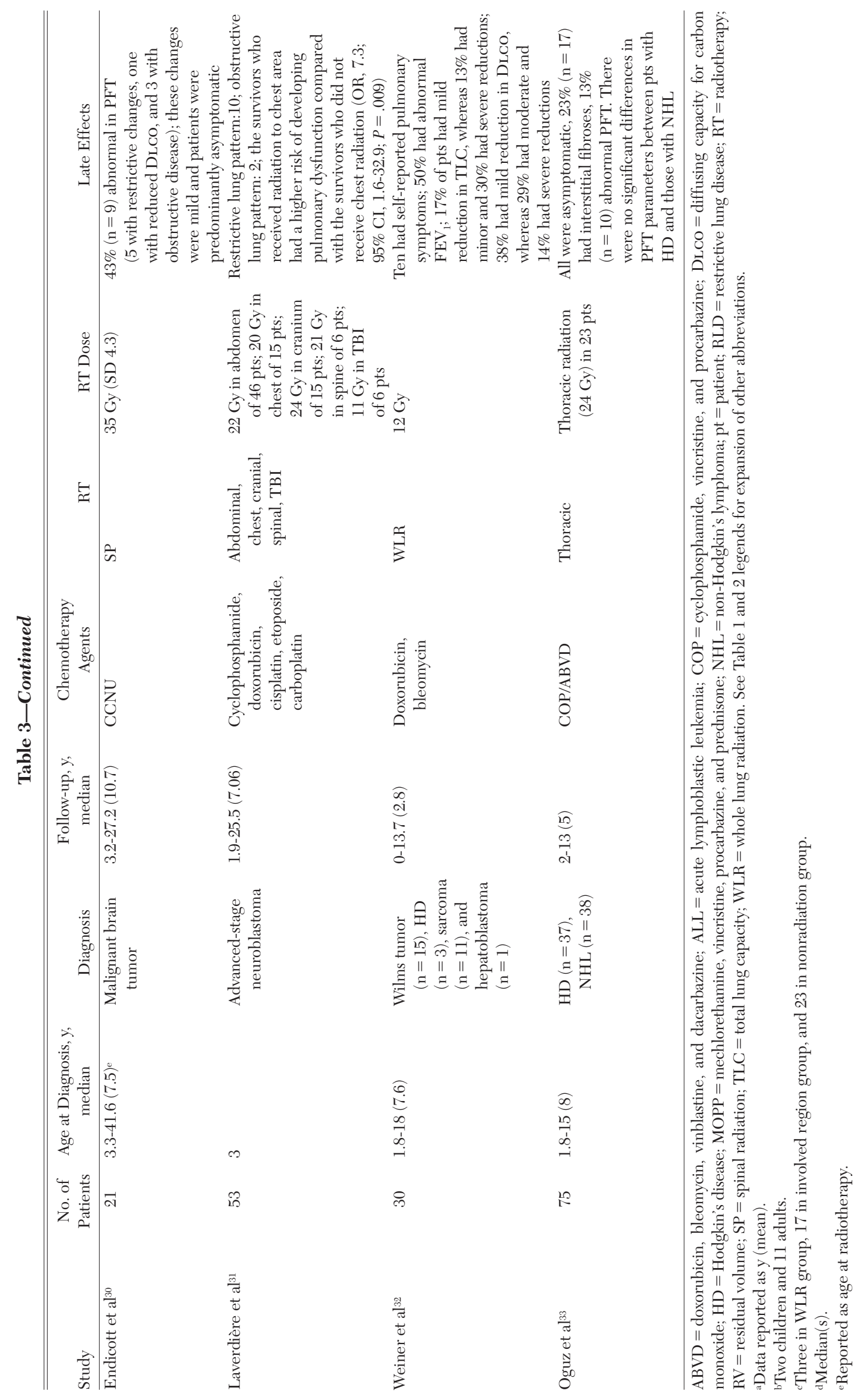


In a cohort study of 38 survivors of childhood-onset ALL, $>50 \%$ had one or more abnormalities in PFTs. ${ }^{26}$ Similar data were reported in another study on a mixed cohort (15 ALL and 14 solid-tumor survivors), in which $48 \%$ had pulmonary function abnormalities. ${ }^{15}$ In a study by Jenney et $\mathrm{al}^{24}$ of lung function and exercise capacity in 70 survivors of childhood leukemia at a median of 6 years after diagnosis, $>50 \%$ of survivors had lower lung volumes and impaired maximal exercise capacity with a reduction of maximal workload, maximal oxygen uptake, and maximal ventilation than normal controls. Exercise performance at submaximal levels was also affected. Of note, onehalf of the subjects who participated in the study had chest infection during, or subsequent to, their treatment of leukemia. It is known that children who undergo acute respiratory insult may develop more chronic problems as they age. ${ }^{70}$ This was confirmed in a multivariate analysis, ${ }^{24}$ in which chest infection occurring during treatment was identified as a risk factor for reduced lung volumes as well as transfer factor. Other risk factors identified for reduced lung volumes in childhood leukemia were cyclophosphamide and craniospinal irradiation, whereas reduced transfer factors were doxorubicin, craniospinal irradiation, and HSCT.

\section{Chemotherapy-Induced Injury}

Previous investigations that have documented that pulmonary function is compromised by exposure to specific chemotherapeutic agents, including bleomycin, carmustine (BCNU), lomustine (CCNU), busulfan, and cyclophosphamide are summarized in Table 4.

Bleomycin-Induced Pulmonary Toxicities: Several distinct pulmonary syndromes are associated with bleomycin exposure, including bronchiolitis obliterans organizing pneumonia (BOOP), eosinophilic hypersensitivity, and, most commonly, interstitial pneumonia, which may ultimately progress to fibrosis. ${ }^{71}$ The onset of pulmonary fibrosis generally occurs several months after completion of therapy. At present, the pathogenesis of bleomycin-induced pulmonary toxicity is not well understood. However, bleomycin is poorly metabolized in the lung because this organ has low levels of the bleomycin-detoxifying enzyme, bleomycin hydrolase. ${ }^{72}$ Bleomycin accumulation damages endothelial cells in lung vasculature, resulting in accumulation of inflammatory cells (macrophages, lymphocytes, and neutrophils) and fibroblasts in the lung parenchyma. ${ }^{71-73}$ The effects of bleomycin can be harmful and even potentially fatal. ${ }^{73}$ Research shows that bleomycin at total cumulative doses of 400 units is associated with the development of fibrosis in $10 \%$ of adult patients without other risk factors, and a death rate of $1 \%$ to $2 \%$ among those patients. Below this threshold, the incidence of pulmonary toxicity is estimated to be between $3 \%$ and $5 \% .{ }^{74}$

Little has been written on bleomycin toxicity in childhood cancer survivors. In a study by Hale et al, ${ }^{37}$ PFTs in 13 children treated for germ cell tumors with bleomycin (median dosage, $120 \mathrm{mg} / \mathrm{m}^{2}$ ) revealed pulmonary dysfunction in eight patients. Mefferd et al ${ }^{34}$ demonstrated pulmonary dysfunction by exposure to bleomycin (a maximum dose of 60 units $/ \mathrm{m}^{2}$ ) among surviving children with HL.

Concomitant or subsequent thoracic irradiation, administration of other chemotherapeutic agents, and/or oxygen therapy may exacerbate bleomycininduced lung injury. A review of published clinical studies $^{75,76}$ and a randomized trial ${ }^{77}$ indicate that the incidence of pulmonary fibrosis rises when bleomycin and radiotherapy are used together. Cyclophosphamide, vincristine, doxorubicin, and methotrexate with bleomycin have also been reported to increase the risk of fibrosis. ${ }^{7}$

Goldiner et $\mathrm{al}^{78}$ reported that the use of oxygen therapy (mean concentration, 39\%) during and after pulmonary resection in five patients with testicular cancer who were treated with bleomycin $(400 \pm 180 \mathrm{mg})$ 6 to 12 months prior, resulted in $100 \%$ mortality because of respiratory distress. Postmortem examination showed severe alveolar wall damage consistent with bleomycin-induced pulmonary injury. In a subsequent study by Goldiner and Schweizer, ${ }^{79} 12$ patients with similar medical profiles maintained on an oxygen concentration of $\leq 25 \%$ had no respiratory complications. Ingrassia et al ${ }^{80}$ also reported that patients who had previously received bleomycin and then needed oxygen support during surgery were susceptible to the development of lung toxicity. Because activated bleomycin induces its toxicity in part by the production of free radicals, the administration of a high dose of inspired oxygen likely magnifies the risk of toxicity.

Alkylating Agents and Lung Dysfunction: In children, busulfan may be used as part of the conditioning regimen for HSCT. Busulfan-induced toxicity usually develops insidiously. Symptoms include a nonproductive cough, dyspnea, or fever. The average time from initiation of therapy to onset of respiratory symptoms is 3.5 years (range, 8 months to 10 years). ${ }^{81}$ It is unclear whether busulfan-related injury is dose dependent, but there are no reports of lung injury in patients receiving doses of busulfan of $<500 \mathrm{mg}$ in the absence of other toxic agents. ${ }^{82}$ As with other chemotherapeutic agents, concomitant irradiation may magnify the effect of busulfan. The chest radiograph in patients with busulfan toxicity reveals a 


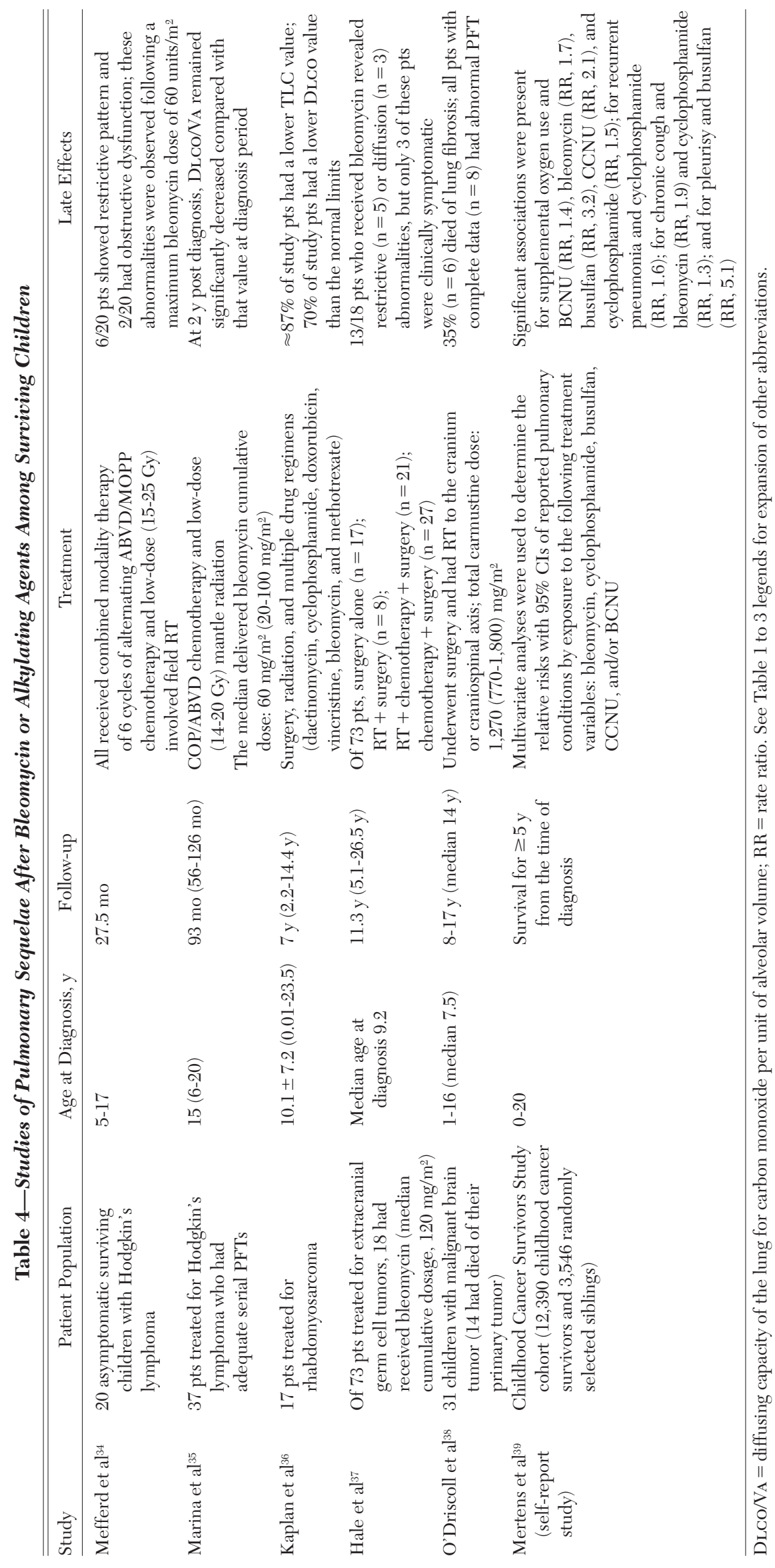


combined alveolar and interstitial infiltrative pattern. Pathologic findings include lymphocytic and plasma cell interstitial infiltration, type 2 hyperplasia, and interstitial fibrosis that are more severe than those seen in other chemotherapy-induced pulmonary toxicities..$^{81,83}$

Cyclophosphamide is an alkylating agent used to treat hematologic and solid-tumor malignancies, in HSCT preparative regimens, and as an immunosuppressant for nonmalignant disorders. Clinical features of cyclophosphamide-induced lung toxicity include dyspnea, fever, cough, gas exchange abnormalities on PFTs, parenchymal infiltrates, and pleural thickening. ${ }^{84}$ Two distinct patterns of cyclophosphamide-induced lung toxicity have been identified. ${ }^{84}$ Early-onset pneumonitis may appear up to 6 months after exposure but resolves with drug withdrawal or corticosteroid administration. Late-onset pneumonitis appears more than 6 months after exposure and does not respond to cessation of cyclophosphamide and/or corticosteroid administration. Late-onset disease is rare $(<1 \%$ of those exposed), but often progresses to fibrosis. ${ }^{85}$ There is no apparent relationship between the development of lung injury and the dose of cyclophosphamide or duration of its use. ${ }^{81,82,86}$

Nitrosoureas are a class of agents with both alkylating and carbamylating activities. They are widely used to treat gliomas and other CNS tumors, and are also included in conditioning for autologous HSCT. ${ }^{81}$ There is a clear relationship between nitrosoureas cumulative dose and lung injury; and long-term injury may be present even without acute evidence of injury. BCNU-induced lung injury occurs in $20 \%$ to $30 \%$ of treated patients overall, ${ }^{76}$ and increases to $50 \%$ in patients who receive a total dose of $>1,500 \mathrm{mg} / \mathrm{m}^{2} .{ }^{.87}$ Lung injury may even occur at lower doses in individuals who have previously received thoracic radiation. ${ }^{86}$ Symptoms such as dyspnea, tachypnea, and nonproductive cough, may develop as early as 1 month after initiation of therapy. ${ }^{88}$

Long-term BCNU toxicity appears as fibrosis. It is insidious in onset, follows a bibasilar reticular pattern, ${ }^{88}$ and seems to be intractably progressive. Corticosteroid therapy is ineffective. ${ }^{81}$ In a review of 17 survivors of childhood brain tumor, restrictive changes with lung fibrosis were reported as long as 25 years after exposure to BCNU at $100 \mathrm{mg} / \mathrm{m}^{2}$ every 6 to 8 weeks for 2 years. ${ }^{38}$ Nine of 17 survivors died of pulmonary fibrosis, two within 3 years of treatment, four within 6 and 13 years of treatment, and three within 13 to 25 years of treatment. Of the eight patients still alive 25 years after treatment, follow-up data from seven survivors showed evidence of upper zone pulmonary fibrosis. ${ }^{89}$

Lung fibrosis has also been associated with similar agents, such as CCNU and methyl-CCNU (semustine), but appears to be less common. ${ }^{88}$ Clinical and histologic findings are similar to those seen for pulmonary toxicity caused by BCNU.

Other Chemotherapy Agents: Methotrexate, teniposide (VM-26), and cytarabine have been associated with noncardiogenic pulmonary edema, a rare acute complication of therapy. ${ }^{83}$ Signs and symptoms are no different from those of noncardiogenic pulmonary edema associated with other causes. ${ }^{83}$ Methotrexateinduced pulmonary toxicity may manifest as hypersensitivity pneumonitis, which is typically associated with rapid reversal and complete recovery after drug withdrawal. 86,88

The taxanes are a group of new-generation anticancer agents used broadly in adult cancer protocols. Their use is evolving in pediatric cancer protocols..$^{90}$ These agents are associated with pulmonary toxicity in adults, usually manifested as nonspecific interstitial pneumonitis, diffuse alveolar damage, and pleural effusion. ${ }^{91}$ Gemcitabine has also been recognized to induce pulmonary toxicity, in about $10 \%$ of patients. ${ }^{92}$ Gemcitabine-induced pneumonitis is likely a cytokine-mediated inflammatory reaction of the alveolar capillary wall. It appears as noncardiogenic pulmonary edema, diffuse alveolar damage, or alveolar hemorrhage..$^{93}$

\section{HSCT and Lung Injury}

HSCT is now an established treatment approach for many malignant and nonmalignant diseases. Pulmonary complications are a major cause of posttransplant morbidity and mortality. ${ }^{94}$ In a retrospective review of 363 children undergoing HSCT over a 5 -year period, Eikenberry et al ${ }^{95}$ reported that those with pulmonary complications had higher mortality rates than those who did not $(65 \%$ vs $44 \%, P<.01)$. Pulmonary complications among HSCT patients are heterogeneous in their frequency, timing, and outcomes. ${ }^{96}$ Complications are related to either the transplant process or the transplant preparative regimen, and are divided into four main categories: (1) conditioning regimen toxicity; (2) infectious complications, which occur during the period of hematopoietic and immune reconstitution; (3) noninfectious complications, which occur because of the chemotherapy or radiotherapy used in the conditioning regimen; and (4) complications due to alloreactivity, which occur after allogeneic transplant.

Late Effects of HSCT in Survivors of Childhood Cancer: Table 5 lists the 23 studies of late sequelae after HSCT published from January 1970 to June 2010 among children transplanted primarily for malignancies. Late sequelae after HSCT are characterized 
by complex interactions between the infectious/ noninfectious agents and the lung (Fig 1). Infectious agents are an important source of complications following HSCT in children. Children remain at risk of bacterial and fungal infections if they develop graftvs-host disease (GVHD) and are also at risk of viral infection, particularly reactivation of herpes viruses such as cytomegalovirus. ${ }^{97}$ Ferry et al ${ }^{98}$ reported that the 10-year cumulative incidence of first episode of infection in 112 children was $31 \% \pm 4 \%$ and in nine patients it involved the pulmonary system (gramnegative infection of respiratory tract, $\mathrm{n}=5$; viral influenza with lung extension, $n=2$; pulmonary aspergillosis, $\mathrm{n}=1$; and pneumocystis carinii, $\mathrm{n}=1$ ).

Longitudinal HSCT data in children show that there is a decline in lung volume and diffusing capacity from pretransplant for 3 to 6 months post transplant, partial recovery for 1 to 2 years, and then stabilization for up to 10 years post transplant. ${ }^{43,45,46,48,49,52,55,99}$ The most commonly reported finding is a restrictive ventilatory deficit, sometimes associated with a decrease in DLCO. ${ }^{40,42,43,45,47-49,50,51,53-55,58}$ In a cohort of survivors of childhood hematologic malignancies after allogeneic HSCT $(n=89)$, Inaba et al ${ }^{62}$ showed progressive worsening of pulmonary function measured with forced midexpiratory flow (25\%-75\%), residual volume, TLC, and DLCO during a median follow-up of 8.9 years.

Obstructive disease associated with chronic GVHD can also occur among children who received HSCT. ${ }^{44,55}$ In a retrospective study of 80 children treated with allogeneic HSCT during a 16-year period, Bruno et al ${ }^{55}$ reported mean $\mathrm{FEV}_{1} / \mathrm{FVC}$ values of $<60 \%$ predicted for patients whose chronic GVHD persisted 5 years post HSCT. In a large cross-sectional study, Hoffmeister et al ${ }^{58}$ examined the prevalence of pulmonary dysfunction in survivors of pediatric HSCT, 175 of whom were transplanted for hematologic malignancies and 40 for nonmalignant diseases (median transplant age, 8.3 years; range, $0.3-18.0$ years). PFTs performed 10 years post HSCT showed that $40 \%$ of patients had either restrictive lung deficits or obstructive lung disease.

Both the timing of the transplant and the age at transplant have been indicated as potential risk factors for the development of late-onset pulmonary abnormalities. In a cross-sectional study of 52 children with hematologic malignancies, Cerveri et al ${ }^{51}$ reported that the percentage of patients with pulmonary abnormalities was higher in patients who received HSCT after two or three complete remissions than in those who were transplanted immediately after the first remission ( $54 \%$ vs $21 \%$; $P<.02)$. This is not surprising given that many first-line chemotherapeutic agents such as cyclophosphamide, methotrexate, and cytosine arabinoside have been reported to cause lung toxicity. Quigley et al ${ }^{99}$ reported a trend toward worsening PFTs with increasing age in 25 children receiving HSCT for different neoplastic malignancies. Arvidson et $\mathrm{al}^{43}$ and Leneveu et $\mathrm{al}^{52}$ reported that children transplanted at a young age had better PFT values than those transplanted at an older age.

\section{Thoracic Surgery and Lung Damage}

Surgical resection remains a key component of the treatment of pulmonary metastasis in children. ${ }^{100}$ Children appear to tolerate resection better than do adults. ${ }^{101,102}$ In one study, among adults who were treated for childhood cancer and who were $\geq 30$ years post pulmonary resection, adaptive mechanisms, such as hypertrophy or hyperinflation of the remaining lungs, were present to compensate for the loss in lung tissue in the long term. ${ }^{103}$

\section{Interactions}

Chemotherapy-Radiotherapy Interactions: Numerous studies have shown that radiomimetic drugs such as actinomycin $\mathrm{D},{ }^{104-107}$ bleomycin, ${ }^{107,108}$ cyclophosphamide, ${ }^{106,107}$ and doxorubicin, ${ }^{107,109}$ and multiple radiomimetic drug regimens ${ }^{110}$ magnify the damaging effects of radiation on the lung. Although doxorubicin is not considered a direct pulmonary toxin, it adds to the toxic effects of radiation. ${ }^{9}$ In a study by Verschoore et al, ${ }^{111} 13$ of 24 patients treated with low-dose doxorubicin and chest radiation (40 Gy in 10 fractions) developed pneumonitis.

Chemotherapy-Chemotherapy Interactions: Toxicity is seen at much lower doses than expected when certain drugs are used in combination. Synergism is particularly problematic when nitrosoureas and cyclophosphamide are used together. ${ }^{9}$ As described above, concomitant use of bleomycin and other chemotherapeutic agents, such as cyclophosphamide, vincristine, doxorubicin, or methotrexate magnifies the risk of bleomycin-induced fibrosis. ${ }^{7}$

\section{Other Risk-Based Factors for Lung Damage}

Skeletal growth defects, such as thoracic hypoplasia, scoliosis, and/or kyphosis, are common late effects among children receiving radiotherapy and could reduce lung volumes, resulting in restrictive lung disease. Among 787 children from the National Wilms' Tumor Study 1 and 2 (1969 to 1979), Evans et al ${ }^{112}$ reported that the prevalence of scoliosis was nearly seven times higher in those children receiving radiotherapy $(61.4 \%)$ than in those who did not $(9.4 \%)$. Paulino et al ${ }^{113}$ reported that the actuarial incidence of scoliosis at 5,10 , and 15 years after radiotherapy (10-40 Gy) in 55 children treated for Wilms tumor was $4.8 \% \pm 3.3 \%, 51.8 \% \pm 9.0 \%$, and $56.7 \% \pm 9.3 \% \%$, respectively. 


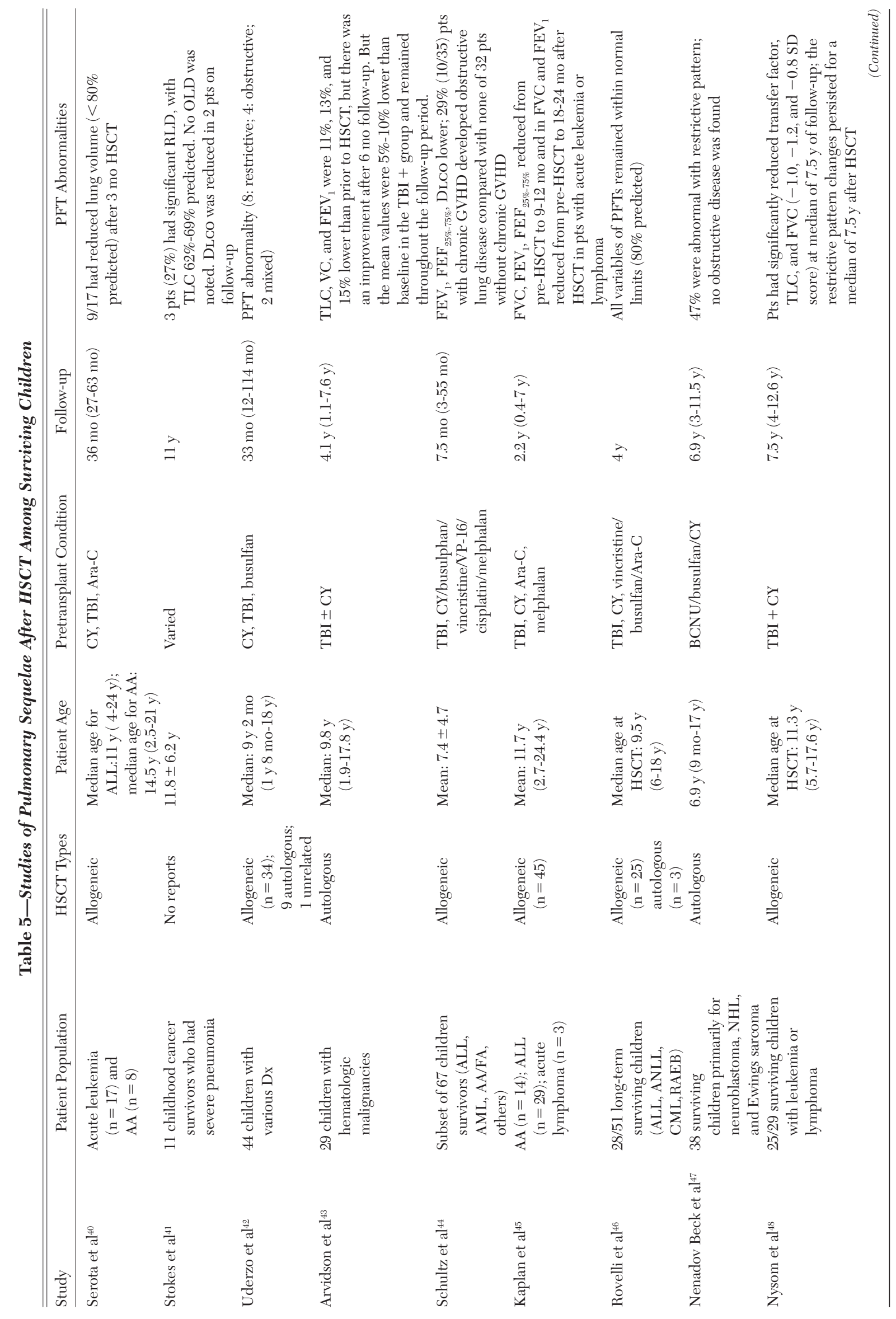




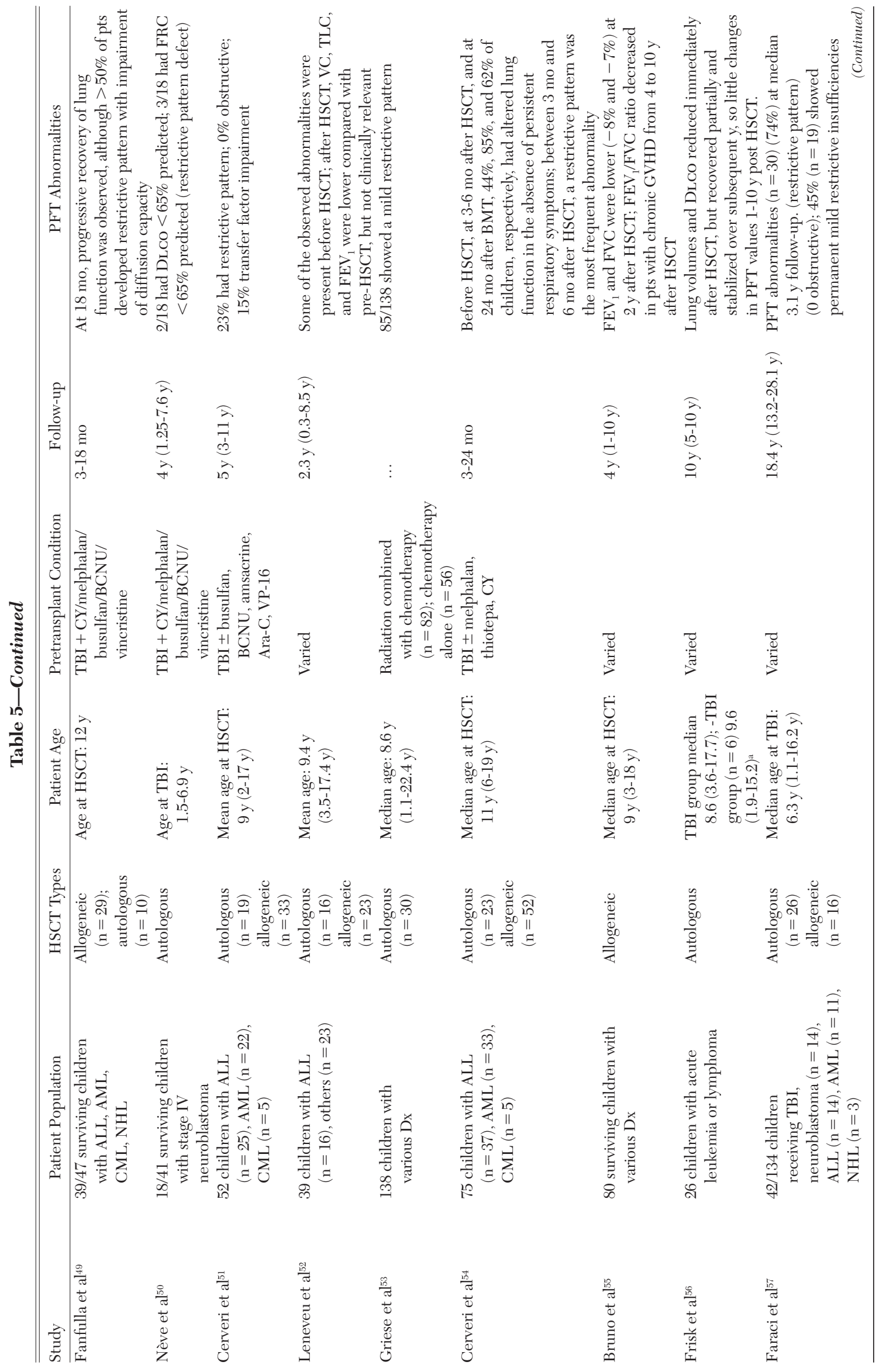




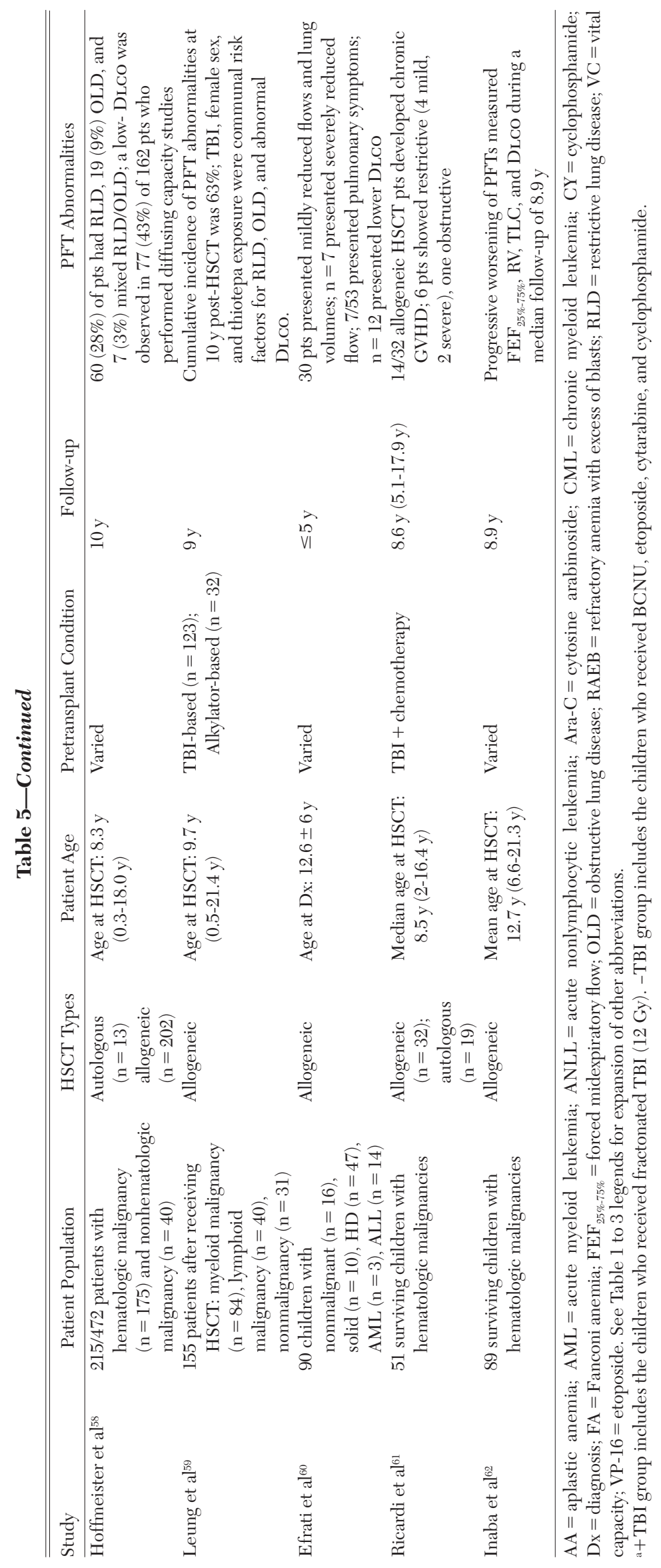




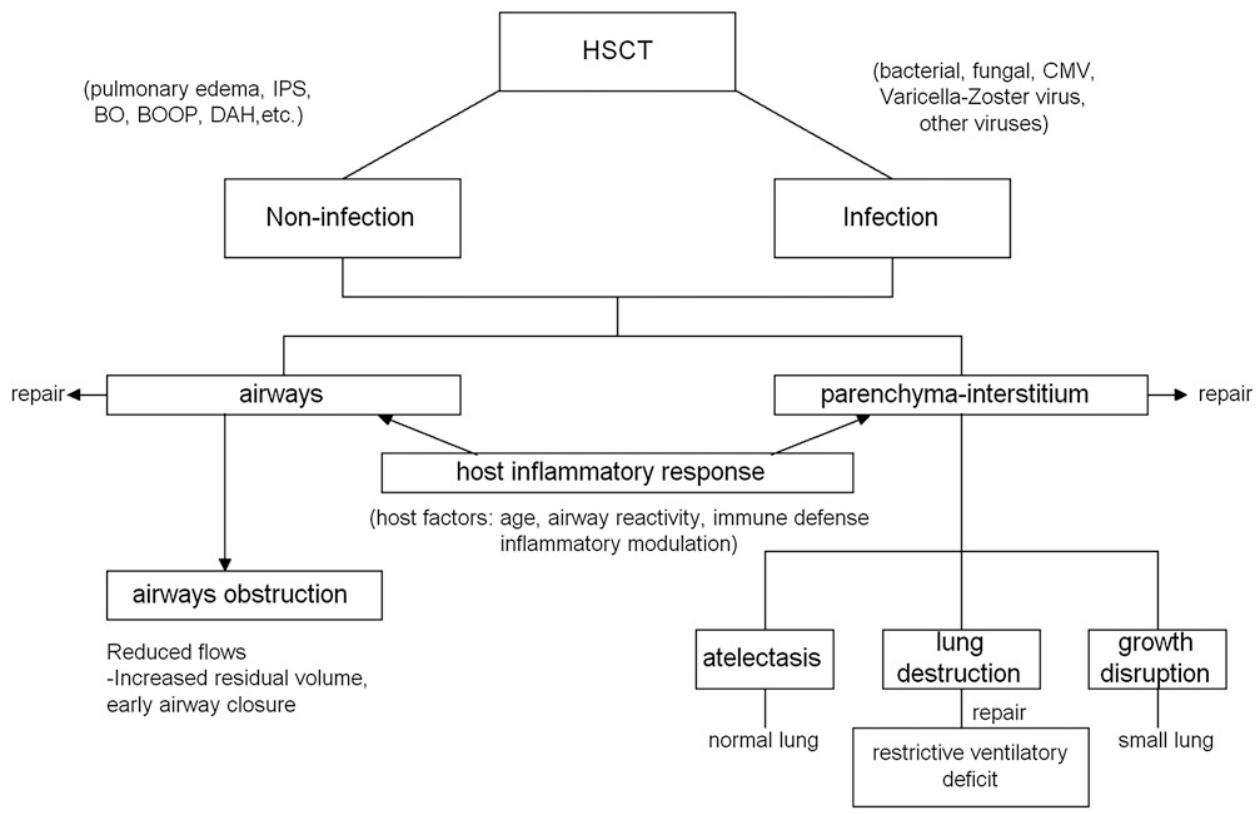

FIGURE 1. Mechanisms for altered pulmonary function and/or growth by HSCT. BO = bronchiolitis obliterans; $\mathrm{BOOP}=$ bronchiolitis obliterans organizing pneumonia; $\mathrm{CMV}=$ cytomegalovirus; $\mathrm{DAH}=$ diffuse alveolar hemorrhage; HSCT = hematopoietic stem cell transplant; IPS = idiopathic pneumonia syndrome.

In addition to their therapeutic exposure to agents designed to treat their disease, children with cancer may have other risk factors that predispose them to long-term pulmonary problems. These include genetic susceptibility to chemotherapy or radiation, underlying asthma or chronic obstructive lung disease, infection, cigarette use, and exposure to environmental respiratory toxins. The effect of early childhood injury during cancer therapy in accelerating the normal decline in lung function that occurs with aging is an important area for future research.

\section{Limitations}

Our review was limited to studies requiring a minimum of 2 years follow-up after completion of cancer-related treatment, and early-onset pulmonary complications related to anticancer modalities were not discussed. Another limitation was that most conclusions in this review were based on prospective serial evaluations, retrospective chart reviews, and cross-sectional investigations in a small cohort in one or multiple institutions. The data from the included studies were limited to published studies. Additionally, it is likely that selection bias is possible because we excluded two articles because their full texts were not available.

\section{ConClusions}

In this systematic review of literature from 1970 to 2010 focused on the known and potential pulmonary late effects among survivors of childhood cancer, the evidence indicates that some treatments necessary to cure malignancy contribute to long-term pulmonary dysfunction. Individual and combined treatment exposures to radiotherapy, bleomycin, alkylating agents, HSCT, and thoracic surgery increase the risk of later lung diseases. Understanding the late effects that result from specific treatment exposures, the contributions of the interactions among therapeutic modalities, and the natural history of evolving pulmonary morbidity over time provides information about host and therapy-related factors that adversely affect outcome.

Although current knowledge facilitates awareness of adverse pulmonary outcomes and identification of high-risk groups, additional investigation is required on many fronts. First, exploring the genetic susceptibility to adverse pulmonary outcomes may provide more information about populations whose risk of a poor outcome precludes use of a particular agent during treatment. ${ }^{114,115}$ Genetic factors may also influence the interaction of therapeutic exposures with lifestyle exposures such as tobacco. Second, progress in understanding the underlying molecular mechanisms that predict pulmonary toxicity post therapy may foster the development of early detection methods and allow early treatment among specific groups of survivors of childhood cancer. For example, several predictive markers of radiation pneumonitis, such as transforming growth factor- $\beta 1$, interleukins, and implicated adhesion molecules have been identified as potentially useful. ${ }^{116,117}$ Third, cancer 
survivorship research is a field that is evolving as new agents, different drug combinations, and altered chemotherapy-radiotherapy sequencing are being tested. Evaluation of the late effects of these exposures will need to be conducted to determine outcomes with more contemporary therapies. Fourth, advances in supportive care, including transfusions and hematopoietic growth factors, also require ongoing surveillance to identify pulmonary late effects. By outlining our current understanding of pulmonary toxicity in childhood cancer survivors and suggesting topics for future research, we hope that this review will serve as a stimulus for the expansion of knowledge about this important aspect of cancer survivorship.

\section{ACKNOWLEDGMENTS}

Author contributions: Dr Huang: contributed to drafting of the manuscript.

Dr Hudson: contributed to critical revision of the manuscript for important intellectual content.

Dr Stokes: contributed to critical revision of the manuscript for important intellectual content.

Dr Krasin: contributed to critical revision of the manuscript for important intellectual content.

Dr Spunt: contributed to critical revision of the manuscript for important intellectual content.

Dr Ness: contributed to critical revision of the manuscript for important intellectual content.

Financial/nonfinancial disclosures: The authors have reported to CHEST the following conflicts of interest: Dr Stokes has received research grant support from Vertex, MPEX, Cystic Fibrosis Foundation, and CF Therapeutics. Drs Huang, Hudson, Krasin, Spunt, and Ness reported that no potential conflicts of interest exist with any companies/organizations whose products or services may be discussed in this article.

\section{REFERENCES}

1. Hampton T. Cancer survivors need better care: new report makes recommendations. JAMA. 2005;294(23):2959-2960.

2. Horner MJ, Ries LAG, Krapcho M, et al, eds. SEER Cancer Statistics Review, 1975-2006, based on November 2008 SEER data submission, posted to the SEER Web site. Bethesda, MD: National Cancer Institute, 2009; http://seer.cancer. gov/csr/1975_2006/. October 2009.

3. Hewitt MWS, Simone JV, eds. Childhood Cancer Survivorship: Improving Care and Quality of Life. Washington, DC: National Academies Press; 2003.

4. Armstrong GT, Liu Q, Yasui Y, et al. Late mortality among 5 -year survivors of childhood cancer: a summary from the Childhood Cancer Survivor Study. J Clin Oncol. 2009;27(14): 2328-2338.

5. Hudson MM, Mertens AC, Yasui Y, et al; Childhood Cancer Survivor Study Investigators. Health status of adult long-term survivors of childhood cancer: a report from the Childhood Cancer Survivor Study. JAMA. 2003;290(12):1583-1592.

6. Mertens AC, Yasui Y, Neglia JP, et al. Late mortality experience in five-year survivors of childhood and adolescent cancer: the Childhood Cancer Survivor Study. J Clin Oncol. 2001;19(13):3163-3172.

7. Abid SH, Malhotra V, Perry MC. Radiation-induced and chemotherapy-induced pulmonary injury. Curr Opin Oncol. 2001;13(4):242-248.
8. Liles A, Blatt J, Morris D, et al; Children’s Oncology Group. Monitoring pulmonary complications in long-term childhood cancer survivors: guidelines for the primary care physician. Cleve Clin J Med. 2008;75(7):531-539.

9. McDonald S, Rubin P, Phillips TL, Marks LB. Injury to the lung from cancer therapy: clinical syndromes, measurable endpoints, and potential scoring systems. Int J Radiat Oncol Biol Phys. 1995;31(5):1187-1203.

10. Hudson MM, Mulrooney DA, Bowers DC, et al. High-risk populations identified in Childhood Cancer Survivor Study investigations: implications for risk-based surveillance. J Clin Oncol. 2009;27(14):2405-2414.

11. West SKV, Carey TS, Lohr KN, McKoy N, Sutton SF, Lux L. Systems to Rate the Strength of Scientific Evidence. Evidence Report/Technology Assessment. Rockville, MD: Agency for Healthcare Research and Quality; 2002. AHRQ Publication No. 290-297-0011.

12. Wohl ME, Griscom NT, Traggis DG, Jaffe N. Effects of therapeutic irradiation delivered in early childhood upon subsequent lung function. Pediatrics. 1975;55(4):507-516.

13. Littman P, Meadows AT, Polgar G, Borns PF, Rubin E. Pulmonary function in survivors of Wilm's tumor. Patterns of impairment. Cancer. 1976;37(6):2773-2776.

14. Benoist MR, Lemerle J, Jean R, Rufin P, Scheinmann P, Paupe J. Effects of pulmonary function of whole lung irradiation for Wilm's tumour in children. Thorax. 1982;37(3):175-180.

15. Miller RW, Fusner JE, Fink RJ, et al. Pulmonary function abnormalities in long-term survivors of childhood cancer. Med Pediatr Oncol. 1986;14(4):202-207.

16. Shaw NJ, Tweeddale PM, Eden OB. Pulmonary function in childhood leukaemia survivors. Med Pediatr Oncol. $1989 ; 17(2): 149-154$

17. Mäkipernaa A, Heino M, Laitinen LA, Siimes MA. Lung function following treatment of malignant tumors with surgery, radiotherapy, or cyclophosphamide in childhood. A follow-up study after 11 to 27 years. Cancer. 1989;63(4): 625-630.

18. Shapiro SJ, Shapiro SD, Mill WB, Campbell EJ. Prospective study of long-term pulmonary manifestations of mantle irradiation. Int J Radiat Oncol Biol Phys. 1990;19(3):707-714.

19. Shaw NJ, Eden OB, Jenney ME, et al. Pulmonary function in survivors of Wilms' tumor. Pediatr Hematol Oncol. 1991;8(2):131-137.

20. Attard-Montalto SP, Kingston JE, Eden OB, Plowman PN Late follow-up of lung function after whole lung irradiation for Wilms' tumour. Br J Radiol. 1992;65(780):1114-1118.

21. Hudson MM, Greenwald C, Thompson E, et al. Efficacy and toxicity of multiagent chemotherapy and low-dose involved-field radiotherapy in children and adolescents with Hodgkin's disease. J Clin Oncol. 1993;11(1):100-108.

22. Horning SJ, Adhikari A, Rizk N, Hoppe RT, Olshen RA. Effect of treatment for Hodgkin's disease on pulmonary function: results of a prospective study. J Clin Oncol. 1994; 12(2):297-305

23. Jakacki RI, Schramm CM, Donahue BR, Haas F, Allen JC. Restrictive lung disease following treatment for malignant brain tumors: a potential late effect of craniospinal irradiation. J Clin Oncol. 1995;13(6):1478-1485.

24. Jenney ME, Faragher EB, Jones PH, Woodcock A. Lung function and exercise capacity in survivors of childhood leukaemia. Med Pediatr Oncol. 1995;24(4):222-230.

25. Turner-Gomes SO, Lands LC, Halton J, et al. Cardiorespiratory status after treatment for acute lymphoblastic leukemia. Med Pediatr Oncol. 1996;26(3):160-165.

26. Bossi G, Cerveri I, Volpini E, et al. Long-term pulmonary sequelae after treatment of childhood Hodgkin's disease. Ann Oncol. 1997;8(suppl 1):19-24. 
27. Nysom K, Holm K, Olsen JH, Hertz H, Hesse B. Pulmonary function after treatment for acute lymphoblastic leukaemia in childhood. Br J Cancer. 1998;78(1):21-27.

28. Nysom K, Holm K, Hertz H, Hesse B. Risk factors for reduced pulmonary function after malignant lymphoma in childhood. Med Pediatr Oncol. 1998;30(4):240-248.

29. Saenz NC, Hass DJ, Meyers P, et al. Pediatric chest wall Ewing's sarcoma. J Pediatr Surg. 2000;35(4):550-555.

30. Endicott TJ, Fisher BJ, Wong E, Paterson NA, Gaspar LE, Bauman M. Pulmonary sequelae after electron spinal irradiation. Radiother Oncol. 2001;60(3):267-272.

31. Laverdière C, Cheung NK, Kushner BH, et al. Long-term complications in survivors of advanced stage neuroblastoma. Pediatr Blood Cancer. 2005;45(3):324-332.

32. Weiner DJ, Maity A, Carlson CA, Ginsberg JP. Pulmonary function abnormalities in children treated with whole lung irradiation. Pediatr Blood Cancer. 2006;46(2):222-227.

33. Oguz A, Tayfun T, Citak EC, et al. Long-term pulmonary function in survivors of childhood Hodgkin disease and non-Hodgkin lymphoma. Pediatr Blood Cancer. 2007;49(5): 699-703.

34. Mefferd JM, Donaldson SS, Link MP. Pediatric Hodgkin's disease: pulmonary, cardiac, and thyroid function following combined modality therapy. Int J Radiat Oncol Biol Phys. 1989;16(3):679-685.

35. Marina NM, Greenwald CA, Fairclough DL, et al. Serial pulmonary function studies in children treated for newly diagnosed Hodgkin's disease with mantle radiotherapy plus cycles of cyclophosphamide, vincristine, and procarbazine alternating with cycles of doxorubicin, bleomycin, vinblastine, and dacarbazine. Cancer. 1995;75(7):1706-1711.

36. Kaplan E, Sklar C, Wilmott R, Michaels S, Ghavimi F. Pulmonary function in children treated for rhabdomyosarcoma. Med Pediatr Oncol. 1996;27(2):79-84.

37. Hale GA, Marina NM, Jones-Wallace D, et al. Late effects of treatment for germ cell tumors during childhood and adolescence. J Pediatr Hematol Oncol. 1999;21(2):115-122.

38. O'Driscoll BR, Hasleton PS, Taylor PM, Poulter LW, Gattameneni HR, Woodcock AA. Active lung fibrosis up to 17 years after chemotherapy with carmustine (BCNU) in childhood. N Engl J Med. 1990;323(6):378-382.

39. Mertens AC, Yasui Y, Liu Y, et al; Childhood Cancer Survivor Study. Pulmonary complications in survivors of childhood and adolescent cancer. A report from the Childhood Cancer Survivor Study. Cancer. 2002;95(11):2431-2441.

40. Serota FT, August CS, Koch PA, Fox W, D’Angio GJ. Pulmonary function in patients undergoing bone marrow transplantation. Med Pediatr Oncol. 1984;12(2):137-143.

41. Stokes DC, Feldman S, Sanyal SK, Mackert PW. Pulmonary function following varicella-zoster pneumonia in children with leukemia. Pediatr Pulmonol. 1987;3(4):236-241.

42. Uderzo C, Rovelli A, Meloni G, et al. Evaluation of late side-effects after bone marrow transplantation in children with leukemia. Bone Marrow Transplant. 1991;8(suppl 1): 44-46.

43. Arvidson J, Bratteby LE, Carlson K, et al. Pulmonary function after autologous bone marrow transplantation in children. Bone Marrow Transplant. 1994;14(1):117-123.

44. Schultz KR, Green GJ, Wensley D, et al. Obstructive lung disease in children after allogeneic bone marrow transplantation. Blood. 1994;84(9):3212-3220.

45. Kaplan EB, Wodell RA, Wilmott RW, Leifer B, Lesser ML, August CS. Late effects of bone marrow transplantation on pulmonary function in children. Bone Marrow Transplant. 1994;14(4):613-621.

46. Rovelli A, Pezzini C, Silvestri D, Tana F, Galli MA, Uderzo C. Cardiac and respiratory function after bone marrow trans- plantation in children with leukaemia. Bone Marrow Transplant. 1995;16(4):571-576.

47. Nenadov Beck M, Meresse V, Hartmann O, Gaultier C. Long-term pulmonary sequelae after autologous bone marrow transplantation in children without total body irradiation. Bone Marrow Transplant. 1995;16(6):771-775.

48. Nysom K, Holm K, Hesse B, et al. Lung function after allogeneic bone marrow transplantation for leukaemia or lymphoma. Arch Dis Child. 1996;74(5):432-436.

49. Fanfulla F, Locatelli F, Zoia MC, et al. Pulmonary complications and respiratory function changes after bone marrow transplantation in children. Eur Respir J. 1997;10(10): 2301-2306.

50. Nève V, Foot AB, Michon J, Fourquet A, Zucker JM, Boulé M. Longitudinal clinical and functional pulmonary follow-up after megatherapy, fractionated total body irradiation, and autologous bone marrow transplantation for metastatic neuroblastoma. Med Pediatr Oncol. 1999;32(3):170-176.

51. Cerveri I, Zoia MC, Fulgoni P, et al. Late pulmonary sequelae after childhood bone marrow transplantation. Thorax. 1999;54(2):131-135.

52. Leneveu H, Brémont F, Rubie H, et al. Respiratory function in children undergoing bone marrow transplantation. Pediatr Pulmonol. 1999;28(1):31-38.

53. Griese M, Rampf U, Hofmann D, Führer M, Reinhardt D, Bender-Götze C. Pulmonary complications after bone marrow transplantation in children: twenty-four years of experience in a single pediatric center. Pediatr Pulmonol. 2000;30(5): 393-401.

54. Cerveri I, Fulgoni P, Giorgiani G, et al. Lung function abnormalities after bone marrow transplantation in children: has the trend recently changed? Chest. 2001;120(6):1900-1906.

55. Bruno B, Souillet G, Bertrand Y, Werck-Gallois MC, So Satta A, Bellon G. Effects of allogeneic bone marrow transplantation on pulmonary function in 80 children in a single paediatric centre. Bone Marrow Transplant. 2004;34(2): 143-147.

56. Frisk P, Arvidson J, Bratteby LE, Hedenström H, Lönnerholm G. Pulmonary function after autologous bone marrow transplantation in children: a long-term prospective study. Bone Marrow Transplant. 2004;33(6):645-650.

57. Faraci M, Barra S, Cohen A, et al. Very late nonfatal consequences of fractionated TBI in children undergoing bone marrow transplant. Int J Radiat Oncol Biol Phys. 2005; 63(5):1568-1575.

58. Hoffmeister PA, Madtes DK, Storer BE, Sanders JE. Pulmonary function in long-term survivors of pediatric hematopoietic cell transplantation. Pediatr Blood Cancer. 2006;47(5):594-606.

59. Leung W, Ahn H, Rose SR, et al. A prospective cohort study of late sequelae of pediatric allogeneic hematopoietic stem cell transplantation. Medicine (Baltimore). 2007;86(4): 215-224.

60. Efrati O, Toren A, Duskin H, et al. Pulmonary function studies in children treated by chemoradiotherapy and stem cell transplantation. Pediatr Blood Cancer. 2008;51(5): 684-688.

61. Ricardi U, Filippi AR, Biasin E, et al. Late toxicity in children undergoing hematopoietic stem cell transplantation with TBI-containing conditioning regimens for hematological malignancies. Strahlenther Onkol. 2009;185(suppl 2):17-20.

62. Inaba H, Yang J, Pan J, et al. Pulmonary dysfunction in survivors of childhood hematologic malignancies after allogeneic hematopoietic stem cell transplantation. Cancer. 2010; 116(8):2020-2030.

63. McCahon E. Lung tumours in children. Paediatr Respir Rev. 2006;7(3):191-196. 
64. Grushka JR, Ryckman J, Mueller C, et al. Spindle epithelial tumor with thymus-like elements of the thyroid: a multiinstitutional case series and review of the literature. J Pediatr Surg. 2009;44(5):944-948.

65. Gustavsson A, Eskilsson J, Landberg T, et al. Long-term effects on pulmonary function of mantle radiotherapy in patients with Hodgkin's disease. Ann Oncol. 1992;3(6):455-461.

66. Hassink EA, Souren TS, Boersma LJ, et al. Pulmonary morbidity 10-18 years after irradiation for Hodgkin's disease. Eur J Cancer. 1993;29A(3):343-347.

67. Lund MB, Kongerud J, Nome $\mathrm{O}$, et al. Lung function impairment in long-term survivors of Hodgkin's disease. Ann Oncol. 1995;6(5):495-501.

68. Villani F, De Maria P, Bonfante V, et al. Late pulmonary toxicity after treatment for Hodgkin's disease. Anticancer Res. 1997;17(6D):4739-4742.

69. Villani F, Viviani S, Bonfante V, De Maria P, Soncini F, Laffranchi A. Late pulmonary effects in favorable stage I and IIA Hodgkin's disease treated with radiotherapy alone. Am J Clin Oncol. 2000;23(1):18-21.

70. Strope GL, Stempel DA. Risk factors associated with the development of chronic lung disease in children. Pediatr Clin North Am. 1984;31(4):757-771.

71. Sleijfer S. Bleomycin-induced pneumonitis. Chest. 2001; 120(2):617-624.

72. Cooper JA Jr, Zitnik RJ, Matthay RA. Mechanisms of drug-induced pulmonary disease. Annu Rev Med. 1988;39: 395-404.

73. Chen J, Stubbe J. Bleomycins: towards better therapeutics. Nat Rev Cancer. 2005;5(2):102-112.

74. Jules-Elysee K, White DA. Bleomycin-induced pulmonary toxicity. Clin Chest Med. 1990;11(1):1-20.

75. Eigen H, Wyszomierski D. Bleomycin lung injury in children. Pathophysiology and guidelines for management. Am J Pediatr Hematol Oncol. 1985;7(1):71-78.

76. Weiss RB, Muggia FM. Cytotoxic drug-induced pulmonary disease: update 1980. Am J Med. 1980;68(2):259-266.

77. Hirsch A, Vander Els N, Straus DJ, et al. Effect of ABVD chemotherapy with and without mantle or mediastinal irradiation on pulmonary function and symptoms in early-stage Hodgkin's disease. J Clin Oncol. 1996;14(4):1297-1305.

78. Goldiner PL, Carlon GC, Cvitkovic E, Schweizer O, Howland WS. Factors influencing postoperative morbidity and mortality in patients treated with bleomycin. BMJ. 1978;1(6128):1664-1667.

79. Goldiner PL, Schweizer O. The hazards of anesthesia and surgery in bleomycin-treated patients. Semin Oncol. 1979; 6(1):121-124.

80. Ingrassia TS III, Ryu JH, Trastek VF, Rosenow EC III. Oxygenexacerbated bleomycin pulmonary toxicity. Mayo Clin Proc. 1991;66(2):173-178.

81. Limper AH. Chemotherapy-induced lung disease. Clin Chest Med. 2004;25(1):53-64.

82. Jenney ME. Malignant disease and the lung. Paediatr Respir Rev. 2000;1(3):279-286.

83. Meyer S, Reinhard H, Gottschling S, Nunold H, Graf N. Pulmonary dysfunction in pediatric oncology patients. Pediatr Hematol Oncol. 2004;21(2):175-195.

84. Malik SW, Myers JL, DeRemee RA, Specks U. Lung toxicity associated with cyclophosphamide use. Two distinct patterns. Am J Respir Crit Care Med. 1996;154(6 Pt 1):1851-1856.

85. Segura A, Yuste A, Cercos A, et al. Pulmonary fibrosis induced by cyclophosphamide. Ann Pharmacother. 2001; 35(7-8):894-897.

86. Rossi SE, Erasmus JJ, McAdams HP, Sporn TA, Goodman PC. Pulmonary drug toxicity: radiologic and pathologic manifestations. Radiographics. 2000;20(5):1245-1259.
87. Aronin PA, Mahaley MS Jr, Rudnick SA, et al. Prediction of BCNU pulmonary toxicity in patients with malignant gliomas: an assessment of risk factors. N Engl J Med. 1980;303(4): 183-188.

88. Cooper JA Jr, White DA, Matthay RA. Drug-induced pulmonary disease. Part 1: cytotoxic drugs. Am Rev Respir Dis. 1986;133(2):321-340.

89. Lohani S, O'Driscoll BR, Woodcock AA. 25-year study of lung fibrosis following carmustine therapy for brain tumor in childhood. Chest. 2004;126(3):1007.

90. André N, Meille C. Taxanes in paediatric oncology: and now? Cancer Treat Rev. 2006;32(2):65-73.

91. Charpidou AG, Gkiozos I, Tsimpoukis S, et al. Therapyinduced toxicity of the lungs: an overview. Anticancer Res. 2009;29(2):631-639.

92. Belknap SM, Kuzel TM, Yarnold PR, et al. Clinical features and correlates of gemcitabine-associated lung injury: findings from the RADAR project. Cancer. 2006;106(9):2051-2057.

93. Vahid B, Marik PE. Pulmonary complications of novel antineoplastic agents for solid tumors. Chest. 2008;133(2):528-538.

94. Soubani AO, Miller KB, Hassoun PM. Pulmonary complications of bone marrow transplantation. Chest. 1996;109(4): 1066-1077.

95. Eikenberry M, Bartakova H, Defor T, et al. Natural history of pulmonary complications in children after bone marrow transplantation. Biol Blood Marrow Transplant. 2005;11(1): 56-64.

96. Tichelli A, Rovó A, Gratwohl A. Late pulmonary, cardiovascular, and renal complications after hematopoietic stem cell transplantation and recommended screening practices. Hematology (Am Soc Hematol Educ Program). 2008:125-133.

97. Pizzo PA, Poplack DG. Principles and Practice of Pediatric Oncology. 5th ed. Philadelphia, PA: Lippincott Williams \& Wilkins; 2006:476-500.

98. Ferry C, Gemayel G, Rocha V, et al. Long-term outcomes after allogeneic stem cell transplantation for children with hematological malignancies. Bone Marrow Transplant. 2007; 40(3):219-224.

99. Quigley PM, Yeager AM, Loughlin GM. The effects of bone marrow transplantation on pulmonary function in children. Pediatr Pulmonol. 1994;18(6):361-367.

100. Abel RM, Brown J, Moreland B, Parikh D. Pulmonary metastasectomy for pediatric solid tumors. Pediatr Surg Int. 2004;20(8):630-632.

101. Bolliger CT, Jordan P, Solèr M, et al. Pulmonary function and exercise capacity after lung resection. Eur Respir J. 1996;9(3):415-421.

102. Lezama-del Valle Valle P, Blakely ML, Lobe TE. Physiologic consequences of pneumonectomy. Long-term consequences of pneumonectomy done in children. Chest Surg Clin N Am. $1999 ; 9(2): 485-495$.

103. Laros CD, Westermann CJ. Dilatation, compensatory growth, or both after pneumonectomy during childhood and adolescence. A thirty-year follow-up study. I Thorac Cardiovasc Surg. 1987;93(4):570-576.

104. Cohen IJ, Loven D, Schoenfeld T, et al. Dactinomycin potentiation of radiation pneumonitis: a forgotten interaction. Pediatr Hematol Oncol. 1991;8(2):187-192.

105. Pearson D, Deakin DP, Hendry JH, Moore JV. The interaction of actinomycin D and radiation. Int J Radiat Oncol Biol Phys. 1978;4(1-2):71-73.

106. Phillips TL, Wharam MD, Margolis LW. Modification of radiation injury to normal tissues by chemotherapeutic agents. Cancer. 1975;35(6):1678-1684.

107. Van Houtte P, Danhier S, Mornex F. Toxicity of combined radiation and chemotherapy in non-small cell lung cancer. Lung Cancer. 1994;10(suppl 1):S271-S280. 
108. Einhorn L, Krause M, Hornback N, Furnas B. Enhanced pulmonary toxicity with bleomycin and radiotherapy in oat cell lung cancer. Cancer. 1976;37(5):2414-2416.

109. Ma LD, Taylor GA, Wharam MD, Wiley JM. "Recall” pneumonitis: adriamycin potentiation of radiation pneumonitis in two children. Radiology. 1993;187(2):465-467.

110. Mah K, Keane TJ, Van Dyk J, Braban LE, Poon PY, Hao Y. Quantitative effect of combined chemotherapy and fractionated radiotherapy on the incidence of radiation-induced lung damage: a prospective clinical study. Int J Radiat Oncol Biol Phys. 1994;28(3):563-574.

111. Verschoore J, Lagrange JL, Boublil JL, et al. Pulmonary toxicity of a combination of low-dose doxorubicin and irradiation for inoperable lung cancer. Radiother Oncol. 1987; 9(4):281-288

112. Evans AE, Norkool P, Evans I, Breslow N, D’Angio GJ. Late effects of treatment for Wilms' tumor. A report from the National Wilms' Tumor Study Group. Cancer. 1991;67(2): 331-336.

113. Paulino AC, Wen BC, Brown CK, et al. Late effects in children treated with radiation therapy for Wilms' tumor. Int J Radiat Oncol Biol Phys. 2000;46(5):1239-1246.

114. Franko AJ, Sharplin J, Ward WF, Hinz JM. The genetic basis of strain-dependent differences in the early phase of radiation injury in mouse lung. Radiat Res. 1991;126(3):349-356.

115. Travis EL. Genetic susceptibility to late normal tissue injury. Semin Radiat Oncol. 2007;17(2):149-155.

116. Kong FM, Ao X, Wang L, Lawrence TS. The use of blood biomarkers to predict radiation lung toxicity: a potential strategy to individualize thoracic radiation therapy. Cancer Contr. 2008;15(2):140-150.

117. Provatopoulou X, Athanasiou E, Gounaris A. Predictive markers of radiation pneumonitis. Anticancer Res. 2008; $28(4 \mathrm{C}): 2421-2432$. 